\title{
Cincuentenario de la máquina corazón-pulmón Un relato acerca de los pioneros y héroes y de las circunstancias que llevaron al gran invento que permitió el tratamiento y la cura de las enfermedades del corazón
}

\author{
Ricardo Zalaquett S.
}

\section{Fifty years of the heart-lung machine}

In 1953 DNA was discovered and the Everest was conquered but also a great invention was developed: the heart-lung machine, which allowed the treatment, and in many cases, the cure of most cardiovascular illnesses. In fact, on May 6, 1953 John Gibbon crowned with success the work of his entire life closing for the first time an atrial septal defect in a young woman using a heart-lung machine of his own invention. Before that, surgeons had explored other roads like hypothermia, cooling the patient in a cold water tub and then rapidly performing the surgical correction of a heart malformation. After his first success, the following $4 \mathrm{pa}-$ tients of Gibbon died, which led him to abandon heart surgery and produced a generalized pessimism about extracorporeal circulation. However, a year later Walton Lillehei reverted this situation with the introduction of controlled cross-circulation in which a patient, usually a child, was connected to a "donor", usually his father or mother, whose heart and lung served as a pump and oxigenator, allowing the performance of open heart surgery. Finally, it was Lillehei again who a year later introduced the bubble oxigenator, simple and inexpensive, opening the doors of open heart surgery to all surgeons around the world. For this, and many other reasons, Walton Lillehei is considered by most surgeons as the "Father of Open Heart Surgery". Lillehei visited Chile in 1963 and operated on a patient in the surgical theaters of the Hospital Clínico de la Universidad Católica and was named an Honorary Member of the School of Medicine of this University. Before that, in 1957 Helmut Jaeger at the Hospital Luis Calvo Mackenna performed the first successful surgical closure of an atrial septal defect with extracorporeal circulation in Chile using a De WallLillehei bubble oxigenator (Rev Méd Chile 2003; 131: 1337-44).

(Key Words: Heart defects, congenital; Heart-lung machine; History of Medicine; Surgical procedures, operative)

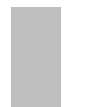

Recibido el 29 de mayo, 2003. Aceptado el 1 de septiembre, 2003.

Departamento de Enfermedades Cardiovasculares, Facultad de Medicina, Pontificia Universidad Católica de Chile, Santiago de Chile.

Correspondencia a: Ricardo Zalaquett S. Departamento de Enfermedades Cardiovasculares. Hospital Clínico Universidad Católica de Chile. Marcoleta \#367 Piso 6, Santiago Chile. Fono: 6333030-3543231. Fax: 6390108.

E mail: rzalaque@med.puc.cl 
S bien 1953 quedará para siempre en la historia de la ciencia como el año del descubrimiento del ADN por Watson y Crick, de inmensa trascendencia para el desarrollo de la biología en general, y cuyos beneficios para la medicina clínica en el último tiempo comienzan a hacerse realidad; 1953 fue también el año de un gran invento tecnológico: la máquina corazón-pulmón, que tuvo un impacto inmediato en el tratamiento, y en muchos casos cura, de la mayoría de las enfermedades cardiovasculares. Ésta, como su nombre lo indica, asume las funciones del corazón y del pulmón permitiendo la cirugía a "corazón abierto", para la corrección de todo tipo de malformaciones congénitas, recambios y reparaciones de las válvulas cardíacas, bypass de las arterias coronarias, reemplazos de la aorta torácica, trasplante de corazón, etc, y fue y es la base para los distintos tipos de corazón artificial que en la actualidad se encuentran en evaluación clínica.

Así, el 6 de mayo de 1953, algunos días antes que el neozelandés Edmund Hillary y el sherpa nepalés Tenzing Norgay conquistaron el monte Everest, John Gibbon Jr, en el Hospital de la Universidad Thomas Jefferson, en Filadelfia, cerró con éxito una comunicación interauricular en una mujer de 18 años llamada Cecilia Bavolek, utilizando una máquina corazón-pulmón de su invención, la que asumió durante $26 \mathrm{~min}$ la función del corazón y del pulmón de la paciente (Figura 1$)^{1}$.

Sin embargo, previo a esta conquista hubo otros pioneros y exploradores que siguieron distintos caminos para efectuar cirugía a "corazón abierto" y que es justo recordarlos.

Hipotermia. Ésta, como procedimiento único y no complementario de la circulación extracorpórea, era inducida colocando al paciente, habitualmente un niño, en una tina de agua fría, luego de la inducción anestésica. Alcanzados los $30^{\circ} \mathrm{C}$ de temperatura corporal la anestesia podía ser interrumpida. En ese momento el paciente era trasladado desde la tina a la mesa de operaciones. A través de una incisión transversal con sección del esternón y apertura de ambas pleuras, la aorta y la arteria pulmonar eran ocluidas, para proceder rápidamente a abrir el corazón y corregir el defecto congénito ${ }^{2}$.

$\mathrm{Si}$ bien fue John Lewis, en la Universidad de Minnesota, quien efectuó por primera vez, en 1952, una operación a corazón abierto exitosa, consistente en el cierre de una comunicación interauricular, utilizando hipotermia y oclusión de cavas, el pionero en esta técnica fue Wilfred Bigelow, de la Universidad de Toronto, quien dedicó gran parte de su vida a la investigación sobre la hipotermia (Figura 2) ${ }^{3-5}$.

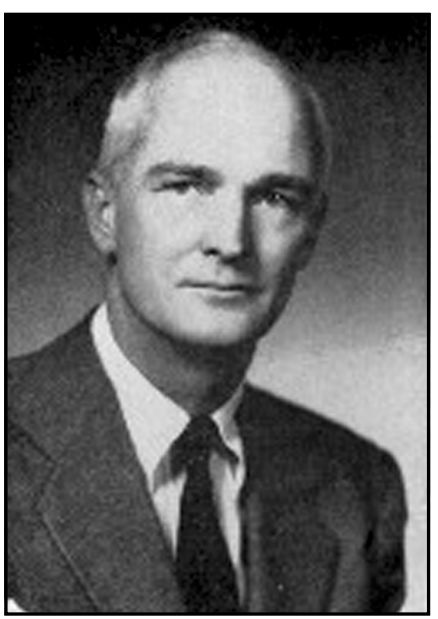

FiguRA 1. John Gibbon Jr., cirujano que efectuó la primera cirugía a corazón abierto utilizando una máquina corazón-pulmón de su propia invención. (Reproducido de Richard Meade, "A History of Thoracic Surgery", 1st Edition, 1961, con autorización de Charles C Thomas, Publisher, Ltd., Sprinfield, Illinois).

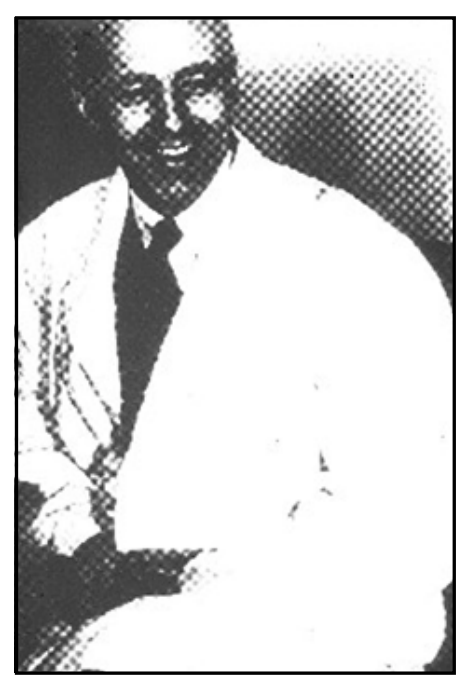

FiguRa 2. Wilfred Bigelow, Cirujano de la Universidad de Toronto, quien dedicó gran parte de su vida a la investigación sobre la hipotermia.

(Reproducido de Andreas P Naef, "The Story of Thoracic Surgery", 1st Edition, 1990, con autorización de Hans Huber Publishers, Toronto. Lewinston, NY. Göttingen. Stuttgart). 
El interés de Bigelow por la hipotermia se inició tempranamente, como interno en la Universidad de Toronto, cuando atendió a un hombre joven por una quemadura por frío de una mano y al que se le iban a amputar los dedos. Posteriormente, como becado de investigación quirúrgica en la Universidad de Johns Hopkins, recordando esta experiencia previa, Bigelow llegó a la conclusión que la naciente cirugía cardíaca necesitaba de algún método que permitiera al cirujano trabajar bajo visión directa en el corazón. Como él mismo escribió en su libro autobiográfico "Cold Hearts": "Una noche desperté con una solución simple para el problema: enfriar todo el cuerpo, reducir los requerimientos de oxígeno, interrumpir la circulación y abrir el corazón"

Sin embargo, el héroe y conquistador en el campo de la hipotermia fue Henry Swan, de la Universidad de Colorado, quien acumuló la mayor experiencia clínica en cirugía a corazón abierto con hipotermia, la que presentó en 1955 al Congreso de la American Surgical Association (Figura 3) ${ }^{2,6}$. Estando la cirugía a corazón cerrado en pleno apogeo, Swan señaló en la introducción de su presentación: "que el ciego pero educado dedo es capaz de hacer mucho dentro del corazón, debe ser amigablemente admitido, y muy admirado. Que debería ser considerado como el mejor método en el largo plazo, es absurdo"2.

Swan presentó en esa oportunidad 59 pacientes operados con la técnica de hipotermia señalada, con una mortalidad de $20 \%$. La conclusión de su trabajo fue: "Con tiempos de oclusión aórtica y pulmonar de $8 \mathrm{~min} 0$ menos, a temperaturas corporales no menores a $26^{\circ} \mathrm{C}$, la técnica es efectiva y segura en lesiones congénitas que puedan ser reparadas por un acceso a través del corazón derecho... es el método de elección en el tratamiento de las estenosis pulmonares valvulares o infundibulares y de los defectos interauriculares" ${ }^{2}$.

$\mathrm{Si}$ bien la hipotermia tuvo una corta vida como método exclusivo para la cirugía a corazón abierto, los fundamentos establecidos experimentalmente por Bigelow y la experiencia clínica acumulada por Swan hicieron que se siga utilizando hasta ahora como complemento de la circulación extracorpórea.

En Chile, la primera operación a corazón abierto con hipotermia se efectuó en el Hospital Van Buren de Valparaíso, en 1956, por una misión del British Council encabezada por Thomas Hol-

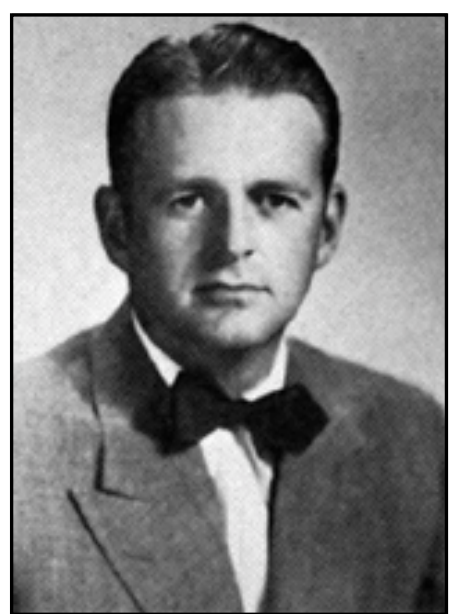

Figura 3. Henry Swan, Cirujano de la Universidad de Colorado, quien acumuló la mayor experiencia clínica en cirugía corazón abierto con hipotermia.

(Reproducido de Richard Meade, "A History of Thoracic Surgery", 1st Edition, 1961, con autorización de Charles C Thomas, Publisher, Ltd., Sprinfield, Illinois).

mes Sellors y consistió en el cierre de una comunicación interauricular?.

Circulación extracorpórea. Clarence Dennis, en la Universidad de Minnesota, en mayo de 1951, intentó por primera vez una operación a corazón abierto con una máquina corazón-pulmón. La paciente era una niña de 6 años portadora supuestamente de una comunicación interauricular. Sin embargo, al abrir el corazón, Dennis comprobó que el defecto era más complicado de lo que él esperaba, al parecer consistente en un síndrome de Lutembacher y la paciente falleció en la mesa de operaciones ${ }^{8}$.

Dos años más tarde, el 6 de mayo de 1953, John Gibbon Jr. cerró exitosamente una comunicación interauricular, utilizando una máquina de circulación extracorpórea inventada por él, coronando así con éxito el trabajo de toda una vida1.

En efecto, John Gibbon (Figura 1) concibió la idea de una máquina corazón-pulmón en 1931, a la edad de 28 años y siendo residente de cirugía en el Hospital General de Massachussets. Una joven mujer a quien 15 días antes se le había efectuado una colecistectomía, presentó una embolia pulmonar masiva. La operación de Trende- 
lemburg para la embolia pulmonar no se había efectuado nunca con éxito en Estados Unidos y sólo se había sido 9 veces en otros países. Por esto, Edwards Churchill, jefe de cirugía de dicho hospital, decidió operar a la paciente sólo como última alternativa. Así, la paciente fue trasladada al pabellón de operaciones donde Churchill y Gibbon efectuaron una vigilia durante toda la noche. A las 8 de la mañana del día siguiente la paciente perdió la conciencia, el pulso se enlenteció y dejó de respirar. Churchill abrió la arteria pulmonar, removió el émbolo y la cerró en 6 min y $30 \mathrm{~s}$, pero la paciente no sobrevivió. Gibbon señaló más tarde que "durante esa larga noche, observando desesperadamente a la paciente luchar por su vida, espontáneamente surgió en mí la idea de que si fuese posible remover en forma continua parte de la sangre azul de las venas distendidas de la paciente, poner oxígeno en esa sangre y permitir que el anhídrido carbónico se separe de ella y luego inyectar de vuelta también en forma continua en las arterias de la paciente esta sangre ahora roja, pudimos haber sido capaces de salvar su vida... podríamos haber efectuado un bypass de la obstrucción embólica de la arteria pulmonar y efectuar parte del trabajo del corazón y de los pulmones de la paciente fuera de su cuerpo"1.

Terminada su residencia y trabajando ya en Filadelfia, en parte dedicado a la investigación y en parte a la práctica clínica, la idea de efectuar el trabajo del corazón y los pulmones fuera del cuerpo persistía muy activa en la mente de Gibbon. Este se daba cuenta que para poder desarrollar una máquina corazón-pulmón capaz de mantener la circulación de un ser humano tenía que dedicarse a ello a tiempo completo, por lo que decidió volver a Boston donde Churchill le dio una beca y un laboratorio. Gibbon inició allí un año de excitante y duro trabajo junto a su esposa Mary Hopkinson (Maly), quien ya había sido su asistente técnico ${ }^{1}$.

Bombear la sangre a través de un circuito no era difícil. Rápidamente desarrollaron un eficiente tipo de válvulas para permitir un flujo unidireccional de la sangre. Para lograr un rápido intercambio de gases era necesario una gran superficie de contacto entre la sangre y los gases, para lo cual se requería una capa muy fina de sangre, lo que se conseguía de diferentes maneras. En general, las principales dificultades que tenían eran el espumamiento, la hemólisis y la producción de sustancias vasoconstrictoras en la sangre, producto de la agitación mecánica de ésta. Los animales de experimentación eran gatos, en los que se simulaba un émbolo que ocluía la arteria pulmonar a través de la compresión gradual de ésta, hasta que se producía una caída en la presión arterial y una elevación de la presión venosa. Su esperanza era poder ocluir la arteria pulmonar completamente y mantener las funciones cardiopulmonares del gato exclusivamente con la máquina corazón-pulmón, lo que ocurrió en 1935, demostrando así por primera vez que la vida podía ser mantenida por un circuito extracorpóreo que incluyera un corazón y un pulmón artificial, sin dañar al animal de experimentación. Además, Gibbon y su esposa demostraron que el corazón y los pulmones del animal podían nuevamente asumir la mantención de la circulación por varias horas, después de haber estado conectado a la máquina corazón-pulmón por tiempos tan largos como $39 \mathrm{~min}^{1}$.

Una vez conseguido esto Gibbon y Maly retornaron a Filadelfia para continuar su proyecto en la Universidad de Pensilvania por los siguientes 6 años, hasta que comenzó la segunda guerra mundial, la que interrumpió su trabajo por 4 años. De vuelta de las islas del Pacífico sur, Gibbon reinició su investigación en la Escuela de Medicina de la Universidad Thomas Jefferson, siempre en Filadelfia. El problema entonces era construir un pulmón artificial de mayor capacidad de oxigenación, que les permitiera utilizar la máquina corazón-pulmón en animales más grandes que los gatos e idealmente en seres humanos. Esto se consiguió al cambiar desde el cilindro giratorio a una pantalla de alambre de acero inoxidable, en la que era posible crear turbulencia en la película sanguínea, lo que aumentaba aproximadamente 8 veces la eficiencia del intercambio gaseoso. Con esto, la mortalidad de los animales de experimentación de mayor tamaño, en la mayoría de los casos perros, disminuyó desde $80 \%$ en 1949 a 12\% en 1952, para períodos de circulación extracorpórea de más de $30 \mathrm{~min}$. Finalmente, un año más tarde, John Gibbon materializó con éxito la idea que había concebido 22 años antes en el histórico cierre de la comunicación interauricular de Cecilia Bavolek ${ }^{1}$. 
Hubo 2 factores que le permitieron a Gibbon coronar, con el éxito de efectuar la primera cirugía a corazón abierto exitosa, con circulación extracorpórea, el trabajo de toda su vida, si bien, como Dennis, en 1952 había perdido su primer paciente en la mesa de operaciones.

El primer factor fue que en 1936 Charles Best logró sintetizar heparina en cantidad suficiente para uso clínico. Gibbon se dio inmediatamente cuenta de la importancia de esto para su investigación, logrando obtener de la Universidad de Toronto pequeñas cantidades de heparina. El segundo factor fue que durante unas vacaciones en 1946 conoció a Thomas Watson, presidente de la IBM, quien le dio apoyo tecnológico y financiero, lo que permitió el diseño y la construcción de una máquina corazón-pulmón suficientemente grande y suficientemente eficiente para ser utilizada en humanos ${ }^{1,2}$.

Sin embargo, luego de su primer éxito, Gibbon perdió los 4 pacientes siguientes y abandonó todo intento ulterior, actitud que ha sido una incógnita para muchos, criticada por algunos. Veinte años después de haberse convertido en el primer cirujano que corrigió con éxito un defecto intracardíaco con una máquina corazón pulmón, John Gibbon Jr, un entusiasta tenista, murió a los 69 años, de un segundo infarto miocárdico, mientras jugaba tenis ${ }^{3}$.

El desarrollo de la máquina de circulación extracorpórea Gibbon-IBM fue continuado por John Kirklin, en la Clínica Mayo. Con la ayuda de los ingenieros de esta institución, Kirklin desarrolló el prototipo Mayo-Gibbon-IBM, con que a partir del 22 de mayo de 1955 la Clínica Mayo se convirtió en uno de los dos centros de vanguardia de la cirugía a corazón abierto de la época. El otro centro estaba sólo a algunos kilómetros de distancia y lo dirigía C. Walton Lillihei ${ }^{3}$.

Circulación cruzada controlada. Si el título de "Padre de la Cirugía a Corazón Abierto" que muchos cirujanos han dado a Walton Lillehei (Figura 4) parece exagerado, es, sin embargo, cierto que la naciente cirugía a corazón abierto habría tenido que luchar por varios años más, oscilando entre tímidos intentos y amargos fracasos, si Lillehei no hubiese tomado un camino completamente nuevo y original que lo condujo a un rápido, decisivo y sensacional avance. Académi- co a tiempo completo en la Universidad de Minnesota y genuino representante de los que por los años 50 se conocían como "cirujanos-fisiólogos", y a partir de las publicaciones de Andreasen de comienzos de esa década, que demostraban que el cerebro podía mantenerse vivo con un flujo sanguíneo equivalente a una décima parte del normal, Lillehei desarrolló el llamado "principio del flujo de la vena ácigos": bajo la oclusión de las cavas, un flujo sanguíneo equivalente a aquel que retornaba por las venas ácigos, un cuarto del gasto cardíaco basal en condiciones normales, sería suficiente para efectuar una operación bajo un cortocircuito del corazón por un período de tiempo limitado. Esto hacía posible la circulación cruzada sin sobrecargar el corazón de un "donante" sano, que servía como un "oxigenador", en general el padre o la madre de un niño. Este verdadero tipo de "circulación placentaria" resultaba ideal desde un punto de vista fisiológico, en un tiempo en que todos los otros intentos, con excepción de uno, habían fracasado, probablemente como resultado de los trastomos homeostáticos secundarios a la circulación extracorpórea ${ }^{3,9,10}$.

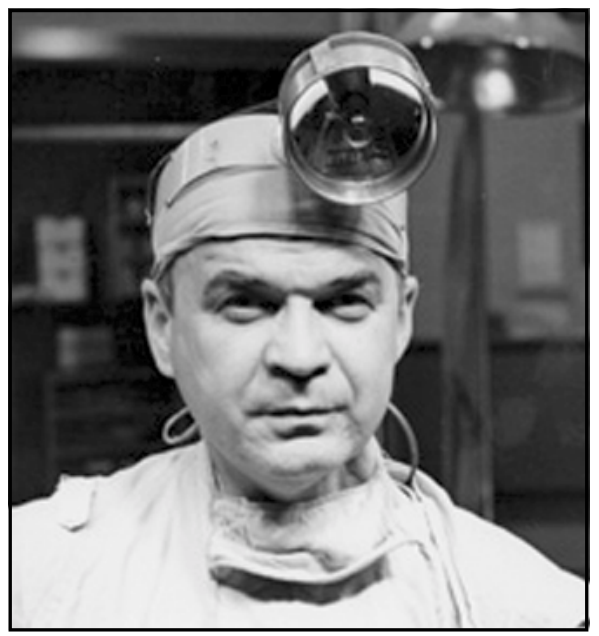

FIgURA 4. C. Walton Lillehei, con su característica luz frontal, para muchos el "Padre de la Cirugía a Corazón Abierto", creador entre muchas otras, de la circulación cruzada controlada y del oxigenador de burbujas.

(Reproducido de Andreas P Naef, "The Story of Thoracic Surgery", 1st Edition, 1990, con autorización de Hans Huber Publishers, Toronto. Lewinston, NY. Göttingen. Stuttgart). 


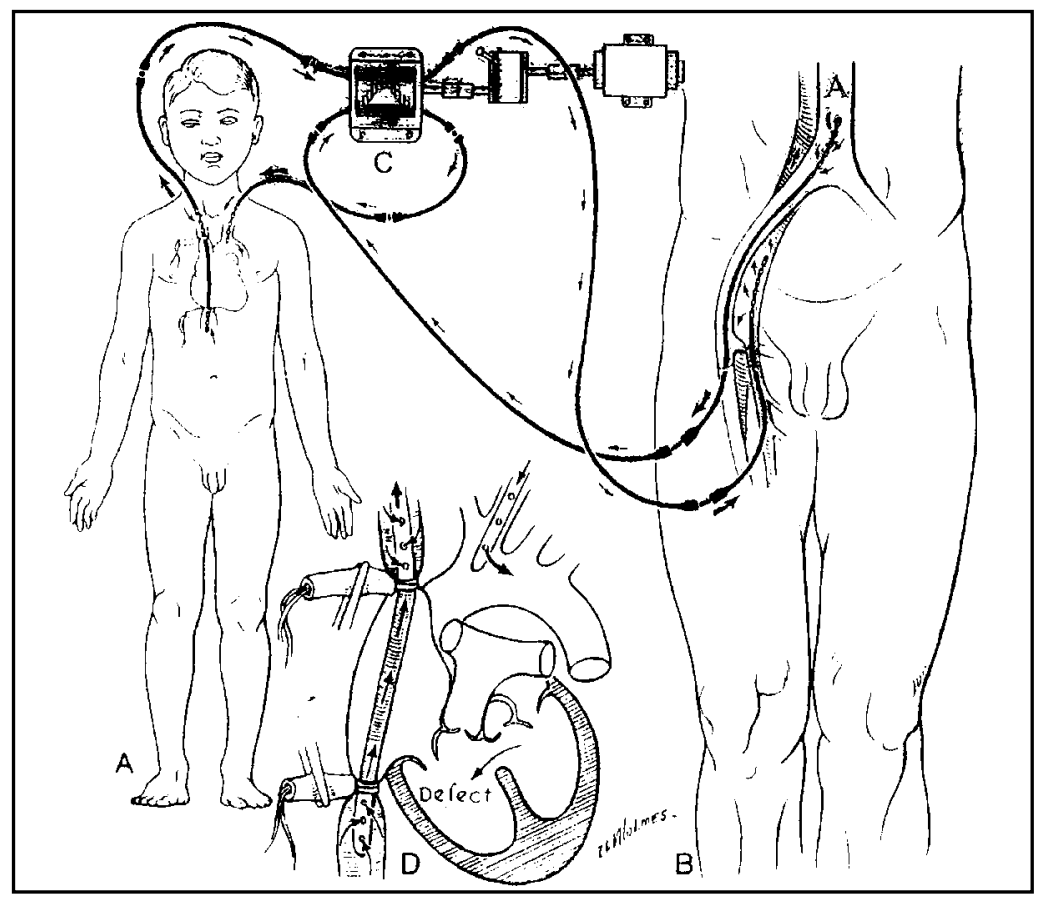

FIgURA 5. Esquema de circulación cruzada controlada, en la que un "donante", habitualmente el padre o la madre de un niño, servía como bomba y oxigenador para efectuar la cirugía a corazón abierto.

(Reproducido de Andreas P Naef, "The Story of Thoracic Surgery", 1st Edition, 1990, con autorización de Hans Huber Publishers, Toronto. Lewinston, NY. Göttingen. Stuttgart).

El 26 de marzo de 1954 Walton Lillehei llevó a cabo el primer cierre de una comunicación interventricular bajo circulación cruzada controlada, a la que siguieron alrededor de 50 operaciones con la misma técnica. El primer niño desafortunadamente falleció a los 11 días de la operación, de una neumonía. Sin embargo, aparentemente Wangensteen, jefe del Departamento de Cirugía de la Universidad de Minnesota, les había aconsejado tener más de un paciente listo para operar por si el primer caso resultaba en un desastre, lo que no era improbable si se recordaba lo que los pioneros de la cirugía pulmonar y a corazón cerrado habían tenido que padecer. Afortunadamente el segundo y tercer pacientes sobrevivieron ${ }^{3,10}$.

La técnica de circulación cruzada controlada consistía en el intercambio recíproco y simultáneo de cantidades iguales de sangre compatible desde el sistema arterial del donante y el sistema venoso del paciente. Para esto se colocaba una cánula venosa en este último a través de la vena yugular interna derecha, dirigida hacia las venas cavas. La arteria subclavia izquierda se disecaba y seccionaba y se introducía en ésta una cánula para recibir la sangre del donante, desde la arteria femoral de éste. La operación se efectuaba con heparina, la que era revertida con protamina, al término de la operación. La sangre venosa del paciente era drenada hacia la vena femoral del donante por medio de una bomba. Durante el procedimiento, el donante era hiperventilado con oxígeno $100 \%$, mientras los pulmones del paciente no se ventilaban (Figura 5) ${ }^{10,11}$.

No es sorpresa que Lillehei fuera severamente criticado por algunos por efectuar una operación con un riesgo potencial de mortalidad de "200\%". Sin embargo, como Lillehei sostuvo tiempo después, "la circulación cruzada fue un paso esencial porque cambió el pesimismo mundial sobre la circulación extracorpórea en optimismo, de la noche a la mañana"3. Pero la crítica no fue universal. Alfred Blalock abrió la discusión del trabajo de Lillehei presentado en 1955 al Congreso de la American Surgical Association, presidido por el mismo Gibbon, titulado "Direct Vision Intracardiac Surgical Correction of the Tetralogy of Fallot, Pentalogy of Fallot and Pulmonary Atresia Defects", afirmando: "debo decir que nunca pensé que viviese para ver el día cuando este tipo de procedimientos quirúrgicos pudiesen efectuar- 
se. Yo quiero felicitar al Dr. Lillehei y al Dr. Varco y a sus asociados por su imaginación, su coraje y su esmero". Pero, agregó: "la respuesta última a este problema será el corazón-pulmón artificial como el desarrollado por nuestro presidente, Dr. Gibbon...". Lillehei cerró la discusión señalando que podía "predecir un futuro brillante en este campo de la cirugía para los oxigenadores artificiales, pero no para los complejos modelos descritos hasta la fecha..." y agregó que estaba "esperando la introducción para uso clínico para ese mismo año de un oxigenador artificial tan simple que costará sólo algunos dólares construir, no tendrá partes móviles y será desechable después de cada uso..., armado con materiales disponibles en la bodega de abastecimiento de un hospital promedio"2. Dieciséis días más tarde, el 13 de mayo de 1955, Lillehei cumplió su predicción con la introducción clínica del oxigenador de burbujas De Wall-Lillehei, corrigiendo con éxito una tetralogía de Fallot en un lactante ${ }^{2}$. Como señala Andreas Naef en su libro "The Story of Thoracic Surgery", mientras la máquina MayoGibbon-IBM era demasiado cara y demasiado compleja para el uso general, el oxigenador de burbujas de hélice casero De Wall-Lillehei conquistó el mundo y ayudó a mucho equipos a embarcarse en la corrección de las malformaciones del corazón de un modo preciso y sin apuros (Figura 6) ${ }^{3}$. Así, con el oxigenador de burbujas, el camino a la cirugía de corazón abierto había sido

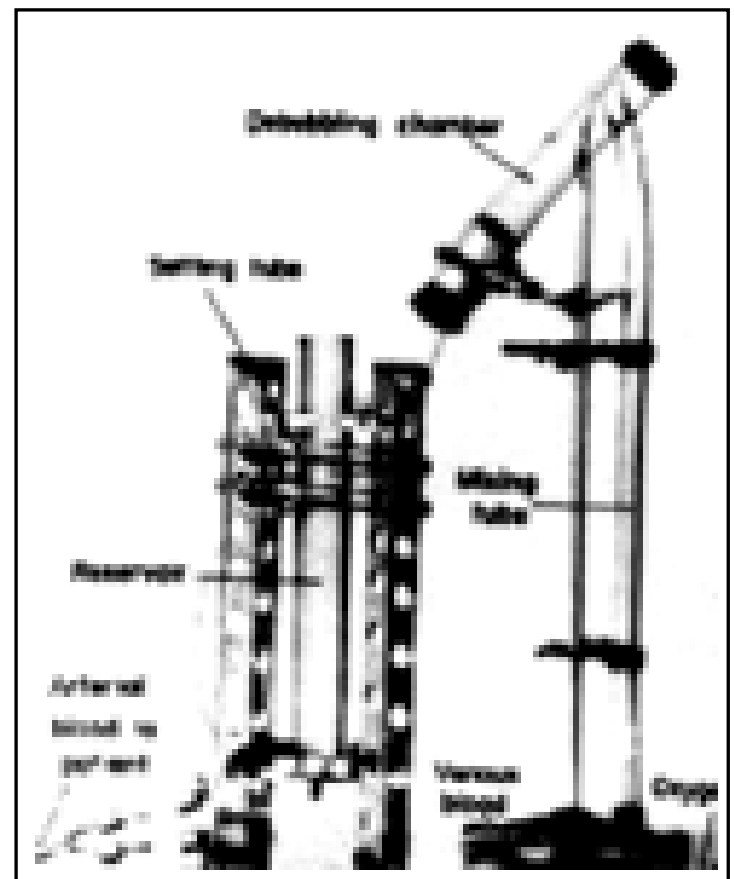

FIgURA 6. Primer prototipo del oxigenador de burbujas De Wall-Lillehei utilizado clínicamente, compuesto del tubo intercambiador de oxígeno (a la derecha), el recipiente para desburbujear (sobre éste) y el reservorio de hélice (a la izquierda).

(Reproducido de Andreas P Naef, "The Story of Thoracic Surgery", 1st Edition, 1990, con autorización de Hans Huber Publishers, Toronto. Lewinston, NY. Göttingen. Stuttgart).

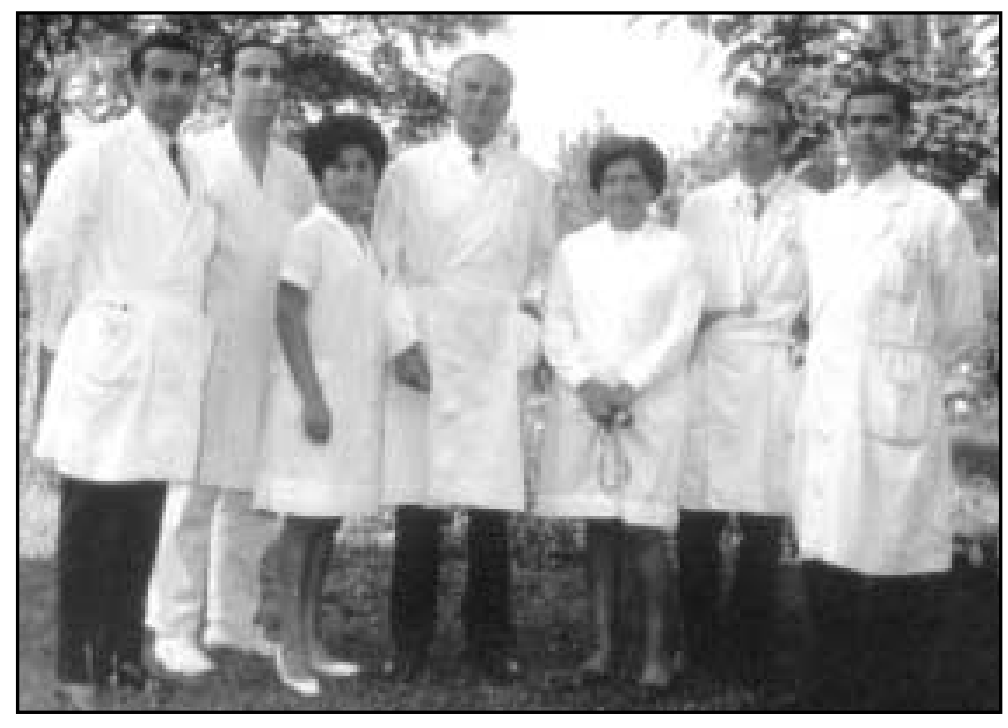

FIGURA 7. Helmuth Jaeger (al centro) y sus colaboradores del Hospital Luis Calvo Mackenna en una fotografía de la época. Jaeger efectuó en 1957 el primer cierre quirúrgico exitoso de una comunicación interauricular utilizando un oxigenador de burbujas De Wall-Lillehei. (Cortesía de Dr. Lorenzo Cubillos). 
abierto para todos. Entre ellos, para Helmuth Jaeger (Figura 7), quien en 1957 efectuó el primer cierre quirúngico exitoso de una comunicación interauricular con circulación extracorpórea en Chile y probablemente en Latinoamérica, utilizando un oxigenador de burbujas De Wall-Lillehei ${ }^{12}$.

En el Hospital Clínico de la Pontificia Universidad Católica, la decisión de iniciar un programa de cirugía a corazón abierto con circulación extracorpórea se tomó en 1958, cuando los cirujanos de este hospital fueron invitados a observar las intervenciones que ese año efectuó Clarens Crafoord, quien encabezó una segunda misión sueca a Chile, practicando en el Hospital San Borja una serie de operaciones a corazón abierto con circulación extracorpórea. La decisión se concretó finalmente en 1961 y se mantiene ininterumpidamente hasta la actualidad, habiéndose efectuado ya más de 13.000 intervenciones con circulación extracorpórea ${ }^{13,14}$.

Walton Lillehei visitó Chile en 1963 como parte de una comitiva del American College of

\section{REFERENCIAS}

1. Gibion JH. Development of the Artifical Heart and Lung Extracorporeal Blood Circuit. JAMA 1968; 206: 1983-6.

2. Ravitch M. A Century of Surgery. Philadelphia: JB Lippincot Company, 1982.

3. NAEF AP. The Story of Thoracic Surgery. Germany: Hans Huber Publishers, 1990.

4. Lewis FS, TAufic M. Closure of Atrial Septal Defect with the Aid of Hypotermia: Experimental Accomplishments and the Report of One Succesful Case. Surgery 1953; 33: 59.

5. Bigelow WG. Cold Hearts. Toronto: Mc Clelland \& Stewart Ltd, 1984.

6. Zalaquett R. Y de cómo se llegó finalmente a la cirugía a corazón abierto. (Parte II). Rev Chil Cardiol 2000; 19: 119-28.

7. Reccius A. Historia y Desarrollo de la Cirugía Torácica en Chile. Valparaíso: Imprenta y Litografía Universo, SA, 1957.

8. Dennis C. Development of a Pump-Oxigenator to Replace the Heart and Lungs: An Apparatus
Cardiology, dictando una serie de conferencias en el Hospital de la Universidad Católica y en la Sociedad Médica de Santiago. En la mañana del lunes 27 de mayo, Lillehei operó en los pabellones de cirugía torácica de dicho hospital una comunicación interventricular en una niña de 6 años. Lillehei fue asistido en esa operación por los cirujanos de la Universidad Católica y la anestesia, perfusión y controles intraoperatorios estuvieron a cargo de anestesistas y cardiólogos de la misma institución ${ }^{10}$. El Mercurio destacó el hecho señalando: "que esto, en contadas oportunidades, hacen los cirujanos extranjeros y sólo cuando cuentan con la seguridad que estarán respaldados por un equipo tanto material como humano, que les dé las suficientes garantías"15.

El 26 de mayo de 1963, en ceremonia, presidida por el Rector Monseñor Alfredo Silva Santiago, Walton Lillehei fue nombrado Miembro Honorario de la Facultad de Medicina de nuestra Universidad. applicable to Human Patients and Application to One Case. Ann Thorac Surg 1951; 134: 70921.

9. Cohen M, Luenei CW. A quantitative Study of the "Azygos Factor" During Vena Caval Occlusion in the Dog. Surg Gyn Obst 1954; 98: 225-32.

10. ZaLaquett R. C Walton Lillehei, MD, PhD (19181999): Héroe y Pionero de la Cirugía a Corazón Abierto. Rev Chil Cardiol 1999: 18: 95-104.

11. Warden H, Cohen M, Read R, Lulehei CW. Controlled Cross - Circulation for Open Intracardiac Surgery. J Thorac Surg 1954; 28: 331-43.

12. JaEger H, EimBKe F, TABoAda E. Consideraciones clínicas sobre 25 intervenciones intracardíacas a visión directa con circulación extracorpórea. Rev Méd Chile 1958; 86: 704.

13. Dubernet J. 40 Años de cirugía cardíaca en el Hospital de la Pontificia Universidad Católica de Chile. Visión de un protagonista. Rev Chil Cardiol 1994; 13: 28-31.

14. Morán S. Historia de la Cirugía Cardíaca. Rev Chil Cirugía 1997; 49: 733-7.

15. El Mercurio. Lunes 27 de mayo de 1963. 